\title{
Extended Release Granule for Suspension Dosage Form
}

National Cancer Institute

\section{Source}

National Cancer Institute. Extended Release Granule for Suspension Dosage Form. NCI

Thesaurus. Code C42921.

A granule intended for administration as a suspension and designed to release active and/or inert ingredient(s) at a controlled, prolonged rate so as to reduce dosing frequency. 